\title{
Stone free rates (SFRs) after retrograde intrarenal surgery (RIRS) and percutaneous nephrolithotomy (PCNL); are we comparing apples with watermelons?
}

\author{
Theodoros Tokas ${ }^{1} \cdot$ Udo Nagele $^{1}$
}

Received: 21 February 2016 / Accepted: 16 March 2016 / Published online: 26 March 2016

(C) Springer-Verlag Berlin Heidelberg 2016

\section{Dear Editor,}

With interest we have read the refreshing meta-analysis published in European Urology by De et al. [1], devoted to standard PCNL, minimally invasive percutaneous nephrolithotomy (MIPP), and RIRS for treating nephrolithiasis. We commend the authors for undertaking such demanding and extensive literature research. They conclude that PCNL offers higher SFRs than MIPP and RIRS. They also purport that RIRS provides lower SFRs than MIPP. Nevertheless the "higher morbidity" of MIPP compared to RIRS is probably due to its less frequent use in daily routine in most centers resulting in less experience and technical know how. However, we believe that some main points are not apparently mentioned and should be taken strictly into consideration.

The preoperative stone size and the stone location constitute important parameters, for choosing the best treatment. Interestingly, by evaluating the SFR data presented by De et al. [1], ten studies were eligible for the meta-analysis. However, only one study [2], presenting 172 MIPPs and 108 RIRs, contributed a $52.7 \%$ weight to the overall and $76.9 \%$ to the MIPP subgroup analysis! Furthermore, the authors reported a statistically significant mean stone size difference $(p \leq 0.004)$ between MIPP $(12.6 \mathrm{~mm})$ and RIRS $(6.8 \mathrm{~mm})$. The fact that this study greatly influences the whole meta-analysis substantiates the inhomogeneity of the data collected. Additionally, De et al. [1] admit that

Udo Nagele

udo.nagele@tilak.at; prof@udonagele.at

Theodoros Tokas

ttokas@yahoo.com

1 Department of Urology and Andrology, General Hospital Hall in Tirol, Milser Str. 10, 6060 Hall in Tirol, Austria some studies assess stone size using maximum stone diameter in $\mathrm{mm}$, while others use the mean area in $\mathrm{mm}^{2}$.

The proper definition of SFR, in other words, the clinically significant residual stone size, is the foothold of proper estimation of treatment outcomes. Many studies report a diameter of $4 \mathrm{~mm}$ [3], or $2 \mathrm{~mm}$ [4]. Nevertheless, small residual fragments require active intervention, in onethird of the cases [5]. In the meta-analysis by De et al. [1], the cutoff SFR values of the different studies are not clearly defined.

The imaging method used for estimating residual fragments and the ideal time to perform it are of utmost importance. Non-contrast CT (NCCT) should always be the preferred method [6-8]. Moreover, recent research has shown that magnified bone windows for NCCT are more accurate for measurement of stones [9]. To date, only several, mainly, PCNL studies use NCCT as a standard follow-up method [2]. Additionally, in many centers, NCCT is performed during the first postoperative week, which could be associated with increased false-positive results from stone dust postoperatively. Moreover, residuals that would pass spontaneously and uneventfully during the early postoperative period are also detected. Therefore, imaging at the end of the first month after surgery is considered optimal [7, 10]. This important parameter should have been properly elucidated in De's study.

The aim of this letter is not to pose criticism but to stimulate further research on the subject, since the current available data remain greatly inhomogeneous. Trying to perform a meta-analysis using the current evidence is like comparing "apples" with "watermelons"! Hence, comparing complications with such heterogeneous groups can also force to misleading conclusions. By focusing our research in all mentioned parameters, the inhomogeneity of our data can be reduced. 


\section{References}

1. De S, Autorino R, Kim FJ, Zargar H, Laydner H, Balsamo R, Torricelli FC, Di Palma C, Molina WR, Monga M, De Sio M (2015) Percutaneous nephrolithotomy versus retrograde intrarenal surgery: a systematic review and meta-analysis. Eur Urol 67(1):125-137. doi:10.1016/j.eururo.2014.07.003

2. Kruck S, Anastasiadis AG, Herrmann TR, Walcher U, Abdelhafez MF, Nicklas AP, Holzle L, Schilling D, Bedke J, Stenzl A, Nagele U (2013) Minimally invasive percutaneous nephrolithotomy: an alternative to retrograde intrarenal surgery and shockwave lithotripsy. World J Urol 31(6):1555-1561. doi:10.1007/ s00345-012-0962-6

3. Takazawa R, Kitayama S, Tsujii T (2012) Successful outcome of flexible ureteroscopy with holmium laser lithotripsy for renal stones $2 \mathrm{~cm}$ or greater. Int J Urol 19(3):264-267. doi:10.1111/j.1442-2042.2011.02931.x

4. Rippel CA, Nikkel L, Lin YK, Danawala Z, Olorunnisomo V, Youssef RF, Pearle MS, Lotan Y, Raman JD (2012) Residual fragments following ureteroscopic lithotripsy: incidence and predictors on postoperative computerized tomography. J Urol 188(6):2246-2251. doi:10.1016/j.juro.2012.08.040

5. Osman Y, Harraz AM, El-Nahas AR, Awad B, El-Tabey N, Shebel H, Shoma AM, Eraky I, El-Kenawy M (2013) Clinically insignificant residual fragments: an acceptable term in the computed tomography era? Urology 81(4):723-726. doi:10.1016/j.urology.2013.01.011

6. Osman Y, El-Tabey N, Refai H, Elnahas A, Shoma A, Eraky I, Kenawy M, El-Kapany H (2008) Detection of residual stones after percutaneous nephrolithotomy: role of nonenhanced spiral computerized tomography. J Urol 179(1):198-200; discussion 200. doi:10.1016/j.juro.2007.08.175

7. Park J, Hong B, Park T, Park HK (2007) Effectiveness of noncontrast computed tomography in evaluation of residual stones after percutaneous nephrolithotomy. J Endourol 21(7):684-687. doi:10.1089/end.2006.0352

8. Gnessin E, Mandeville JA, Handa SE, Lingeman JE (2012) The utility of noncontrast computed tomography in the prompt diagnosis of postoperative complications after percutaneous nephrolithotomy. J Endourol 26(4):347-350. doi:10.1089/end.2011.0504

9. Eisner BH, Kambadakone A, Monga M, Anderson JK, Thoreson AA, Lee H, Dretler SP, Sahani DV (2009) Computerized tomography magnified bone windows are superior to standard soft tissue windows for accurate measurement of stone size: an in vitro and clinical study. J Urol 181(4):1710-1715. doi:10.1016/j. juro.2008.11.116

10. Portis AJ, Laliberte MA, Holtz C, Ma W, Rosenberg MS, Bretzke CA (2008) Confident intraoperative decision making during percutaneous nephrolithotomy: does this patient need a second look? Urology 71(2):218-222. doi:10.1016/j. urology.2007.08.063 